\title{
Spreading of dangerous substances indoors
}

\author{
D. Chudová \\ Technical University of Ostrava, Czech Republic
}

\begin{abstract}
This study deals with the potential possibilities of dispersion and spreading of a concentrated chemical substance (Sarin) indoors during a terrorist attack. The consequences can be seen by using a software program, CONTAM 2.4.
\end{abstract}

Keywords: air handling systems, Sarin, CBR substances, terrorism, CONTAM.

\section{Introduction}

The beginning of the 21 st century, together with increasing industrial growth, is bringing a higher risk of negative effects due to potentially dangerous substances in buildings or other enclosed areas. Reasons for this can be due to human or mechanical error, e.g. spreading of dangerous substances from industrial firms due to leaks, fires or other unintentional means. The bigger concern today though is the intentional attack on property and/or people as a terrorist act.

The contaminant would normally be in the form of smoke during fires, chemical spills or use of CBR substances. Since in all cases the substances are dangerous, and can seriously damage people's health, it is not possible to use these substances for actual testing. One possibility is to exchange the dangerous substance tested with a similar substance that has no dangerous effects. Another, which is thought to be the better possibility, is to use one of the model software programs. This test is then virtual and poses no threat to people, animals or the environment. Today this is the preferred method and the software is being utilized more and more. This software is easily accessible and in certain cases available at no cost and downloadable. In addition the software can be used anywhere.

This study simulates the spreading of Sarin, a dangerous substance, throughout a buildings interior. The most probable spreading of Sarin in a building is through the ventilation system. 


\section{Air handling systems and CBR substances}

Air handling systems are practically a part of every 21 st century building. Ventilation used to assist in maintaining good indoor air quality by diluting and removing pollutants emitted within the space. Ventilation is additionally used for cooling and (particularly in dwellings) to provide oxygen to combustion appliances. Good ventilation is a major contributor to the health and comfort of building occupants. The air handling system is placed in either buildings with people to ensure their good microclimate (houses, apartments, offices, etc.), or to objects with technologies that have an impact on air quality. This study deals with the first type of buildings focusing on areas with large congregations of people.

Today's advancement of processes and equipment for air reuse brings new technical ideas, results and realizations of new air handling systems. The circulating of air can be very easy with only some minor complex parameters requiring precise calculation. In modern buildings these systems are usually used for heating, ventilation and air conditioning and they are often referred to as HVAC systems.

Air handling systems can have other minor functions. An enhanced ventilation system can even minimize a CBR substances terrorist attack and remotely minimize the hazard.

HVAC systems in an object can become the main source and provide a distribution system for a series of dangerous contaminants including CBR substances. Accordingly designed, installed and maintained filtration and air cleaning systems can mitigate the risk of CBR substances both inside and outside of a building by either eliminating or at least lowering the concentration of contaminants circulating within or entering the building from the outside.

When thinking about how air handling systems function and their potential to be used as a device for a CBR substances terrorist attack, the main points we have to consider are as follows:

- An outside attack of buildings with or without use of an HVAC system for distribution of CBR substances

- An inside attack of buildings with or without use of an HVAC system for distribution of CBR substances

- An outdoor massive release of CBR substances not specifically targeted against a particular building

It is also necessary to solve the two main problematic areas:

- Firstly, how to design the building to minimize the possibility of inserting and continuous spreading of CBR substances

- Then, how to minimize the response time and adequately handle the situation if the unfortunate event was to occur

Considering that this problem is not only in newly built buildings, it is necessary to solve the following:

- How to adapt the older buildings to reduce the threat

- Preparation of evacuation plans in case of an attack 
To lower the risk we need a set of complex plans. The decision of which plan to use, depends mainly on the threat profile and the building itself, including the patrons [1].

\section{Simulation spreading of CBR substances in buildings}

There are two possibilities on how to limit the consequences of an attack when a terrorist is using an HVAC system for CBR spreading. The first is to exchange the dangerous substance tested with a similar substance, that doesn't show dangerous effects. This is very expensive and usually hard to do. The second possibility is much more suitable and involves using a mathematical model. In this case the second possibility was chosen, in which we used the CONTAMW 2.4 software for the mathematical modelling. This computer program CONTAMW version 2.4, developed by The National Institute of Standards and Technology (NIST) is a multi-zone indoor air quality and ventilation analysis program designed to help you determine:

- Airflow and pressures - infiltration, exfiltration, and room-to-room airflows and pressure differences in building systems driven by mechanical means, wind pressures acting on the exterior of the building, and buoyancy effects induced by temperature differences between the building and the outside.

- Contaminant concentrations - the dispersal of airborne contaminants transported by these airflows and transformed by a variety of processes including chemical and radio-chemical transformation, adsorption and desorption to building materials, filtration, and deposition to building surfaces.

- Personal exposure - the prediction of exposure of building occupants to airborne contaminants for eventual risk assessment.

CONTAMW can be useful in a variety of applications. Its ability to calculate building airflows and relative pressures between zones of the building is useful for assessing the adequacy of ventilation rates in a building, to determine the variation in ventilation rates over time, to determine the distribution of ventilation air within a building, and to estimate the impact of envelope air tightening efforts on infiltration rates. The program has been used extensively for the design and analysis of smoke management systems. The prediction of contaminant concentrations can be used to determine the indoor air quality performance of buildings before they are constructed and occupied, to investigate the impacts of various design decisions related to ventilation system design and building material selection, to evaluate indoor air quality control technologies, and to assess the indoor air quality performance of existing buildings. Predicted contaminant concentrations can also be used to estimate personal exposure based on occupancy patterns.

The use of CONTAMW version 2.4 to analyze airflow or contaminant migration in a building involves six distinct tasks [3]:

1. Building Idealization

2. SketchPad Representation 


\section{Simulation Scenarios \\ 4. Data Entry \\ 5. Simulation \\ 6. Review \& Record Results}

\section{Task 1 - Building idealization}

Building idealization refers to the simplification of a building into a set of zones that are relevant to the user's goal in performing an analysis. A building can be idealized in a number of ways depending on the building layout, the ventilation system configuration and the problem of interest. This idealization phase of analysis requires some engineering knowledge on the part of the user and is an acquired skill that you can develop through experience in airflow and indoor air quality analysis and by becoming familiar with the theoretical principles and details upon which indoor air quality analysis is based.

\section{Task 2 - SketchPad representation}

Developing the SketchPad representation will be the focus of your interaction with CONTAM. With CONTAM's SketchPad you will be able to draw a diagram - a SketchPad diagram - of your building idealization using drawing tools and libraries of icons to represent components of the building system. CONTAM translates your diagram into a system of equations that will than be used to model the behavior of the building when you perform a simulation.

\section{Task 3 - Simulation scenarios}

If there are no simulation situation plans present, there is a need to develop a detailed procedure and collect all the required data for the simulation. Especially the data related to potential contaminants including CBR Substances and their spreading potential, the filters being used, area occupancy and the operating regime of the air system, etc. The collected data will be used for further developing the safe procedures.

\section{Task 4 - Data entry}

Data entry can be one of the more time-consuming parts of the process of using CONTAM. It involves the determination and input of the numerical values of the parameters associated with each of the SketchPad icons. These icons represent the elements of the building model and include air leakage paths (windows, doors, cracks), ventilation system elements (fans, ducts, vents), contaminant sources, filters, and sinks. Each of these elements is associated with a number of parameters, and you must obtain the values of these parameters for entry into the model. Depending on the element and the application, these values can be obtained from building-specific data, engineering handbooks, and product literature. In many cases, a degree of engineering judgment will be involved. CONTAM allows you to create libraries of these elements that you can use in current and future modelling efforts. 
Task 5 - Simulation

Simulation is the use of CONTAM to solve the system of equations assembled from your SketchPad representation of a building to predict the airflow and contaminant concentrations of interest. This step involves determining the type of analysis that is needed; steady state, transient or cyclical, and a number of other simulation parameters. These parameters depend on the type of analysis you wish to perform (steady state or transient), and include convergence criteria and in the case of a transient analysis, time steps and the duration of the analysis.

Task 6 - Review \& record results

CONTAM allows the user to view the simulation results on the screen and to output them to a file for input to a spreadsheet program or a data analysis program developed by the user. Airflows and pressure differences at each flow element can be viewed directly on the SketchPad. Contaminant concentrations for a zone can also be plotted as a function of time directly from the SketchPad. The user can then decide which data they wish to examine more closely and export these to a tab-delimited text file that can then be imported into a spreadsheet for further analysis.

\section{CONTAM program application example for a real building}

\subsection{Building characteristics}

For our spreading contaminant case study I picked building "C" of Safety Engineering Faculty. It is a three level building with no basement and both sides are connected with other objects. Almost a half of first and second levels are a conference hall for 200 students and a gym. The remaining part of all three levels consists of mostly laboratories and offices. In the first level, in-between the conference hall and the gym, there is an air handling system that is used for the ventilation of the conference hall and laboratories. The next air handling system that is placed in the middle of the third level is used for suction from the laboratories.

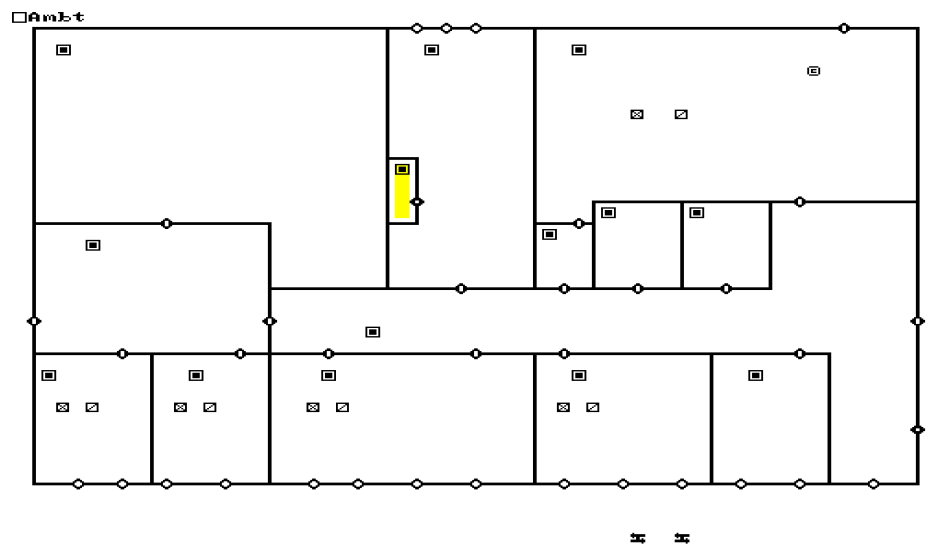

Figure 1. 
All three levels are connected with stairway situated on the left side of the object. To enter the rooms there are one or two wing doors. All of the rooms have windows and in the conference hall and the gym there are fixed windows that cannot be opened. Thus in these areas there is no outside airflow.

\subsection{Leakage definition}

For the simulation of spreading the dangerous substance into the conference hall we used Sarin. Sarin is an extremely toxic substance whose sole application is as a nerve agent. Like other nerve agents, Sarin attacks the nervous system of a living organism. The difference in strength depends on the actual quality of the chemical substance. Sarin is a highly volatile liquid. Inhalation and absorption through the skin pose a great threat. People who absorb a non-lethal dose but do not receive immediate appropriate medical treatment may suffer permanent neurological damage. Death may follow in 30 seconds to 15 minutes after direct inhalation. Initial symptoms following exposure to Sarin are a runny nose, headaches, cough, tightness in the chest and constriction of the pupils. Soon after, the victim has difficulty breathing and experiences nausea and drooling. As the victim continues to lose control of bodily functions, he vomits, defecates and urinates. This phase is followed by twitching and jerking. Ultimately, the victim becomes comatose and suffocates in a series of convulsive spasms and heart attack [4]. With inhalation of Sarin vapor we usually use LCt50=100mg.min.m-3 [5]. Average maximum concentration for out of work environment (GPL) is in 0.000003mg.m-3 [2].

Considering that the terrorists are trying to start a mass confusion and personal fear, we picked the conference hall as a suitable place for Sarin leakage and people's threat by inhaling Sarin vapor. The conference hall is usually easy to access; there are a lot of people, so a good aim for a terrorist attack.

The types of possible air contamination in the conference hall are:

- Sarin inflow into an air ventilation system from the outer limits of the building.

- Sarin inflow into the outlet of the air ventilation system when air recirculation is used.

- Direct Sarin leak into the conference hall.

The outside of the building is monitored by a camera system, so any suspicious moves of unauthorized personnel should be quickly discovered. To use the air recirculation of Sarin in the conference hall would not be the best idea since the ventilation system only re-circulates a small percentage of the air reducing the overall effects of the Sarin. For this reason our simulation uses a direct Sarin leak as a model example.

The leak starts at 9am and Sarin will be spreading for a period of 5 minutes in the amount of $15 \mathrm{ml} / \mathrm{min}$. For the substance to start vaporization into the air it is necessary to use dusting or increase temperature. 


\subsection{Characteristics of air ventilation}

The unit used in the conference hall is a DUPLEX - CT - CHW 12000 with airflow of $12000 \mathrm{~m} 3 / \mathrm{hr}$. The unit can also be used for recirculation. The air will be prepared first by filtration, then either heated up to $25^{\circ} \mathrm{C}$ in winter months or cooled to $18^{\circ} \mathrm{C}$ in summer. Air inflow into the conference hall is done through inlet vents with fire closures. Outflow is below the seats in the conference hall. The air ventilation system will be fixed for inflow and outflow of $10000 \mathrm{~m} 3 / \mathrm{hr}$. Another air ventilation system type DUPLEX - T - CHW 12000 will be used for the venting of the laboratories. This unit doesn't do recirculation.

\subsection{Simulation description}

During the simulation the outside temperatures used were $20^{\circ} \mathrm{C}$ and $8^{\circ} \mathrm{C}$ and the temperature in the conference hall was $20^{\circ} \mathrm{C}$. The wind for infiltration was not considered. Windows were not considered either, since they are not operable and there is no infiltration. We only considered two doors that are not sealed (the doors are used as possible inflows for heat and smoke in case of fire) and the entry door into the conference hall. The rest of the building consists of unsealed windows and doors. For the simulation we have used a hole 2 meters high by $1.1 \mathrm{~mm}$ wide as a standard to replace the windows and doors. We didn't consider any reaction of Sarin with the indoor materials used. Air ventilation system filters, which could affect the Sarin concentration, were also not considered.

Table 1: $\quad$ Simulation time table.

\begin{tabular}{|l|l|l|}
\hline Simulation start & January 1, 2007 & 00.00 a.m. \\
\hline Leakage start & January 2, 2007 & 09.00 a.m. \\
\hline Leakage end & January 2, 2007 & 09.05 a.m. \\
\hline $\begin{array}{l}\text { Air ventilation system } \\
\text { on }\end{array}$ & January 2, 2007 & $\begin{array}{l}07.00 \text { a.m. (if used for } \\
\text { simulation) }\end{array}$ \\
\hline $\begin{array}{l}\text { Air ventilation system } \\
\text { off }\end{array}$ & January 2, 2007 & $\begin{array}{l}08.00 \text { p.m. (if used for } \\
\text { simulation) }\end{array}$ \\
\hline End of simulation & January 5, 2007 & 00.00 a.m. \\
\hline
\end{tabular}

First there was a simulation of a Sarin leak into the conference hall without the air ventilation system with equal inside and outside temperatures of $20^{\circ} \mathrm{C}$. After the leak the conference hall had maximum concentration of $0.12 \mathrm{ppm}$, which remained constant after the leak was completed. The result of the simulation can be seen in figure 2 .

The next simulation was done using the air ventilation system without using any air recirculation. The system was working from $7 \mathrm{am}$ to $8 \mathrm{pm}$. The Sarin leak started at 9am. The results of Sarin concentration in the conference hall are shown in figure 3. 


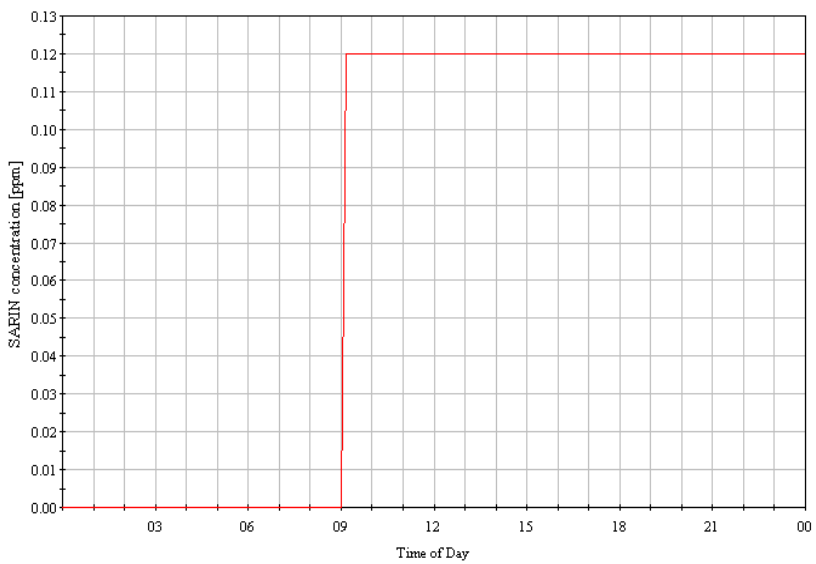

Figure 2: Leak without air ventilation system and infiltration.

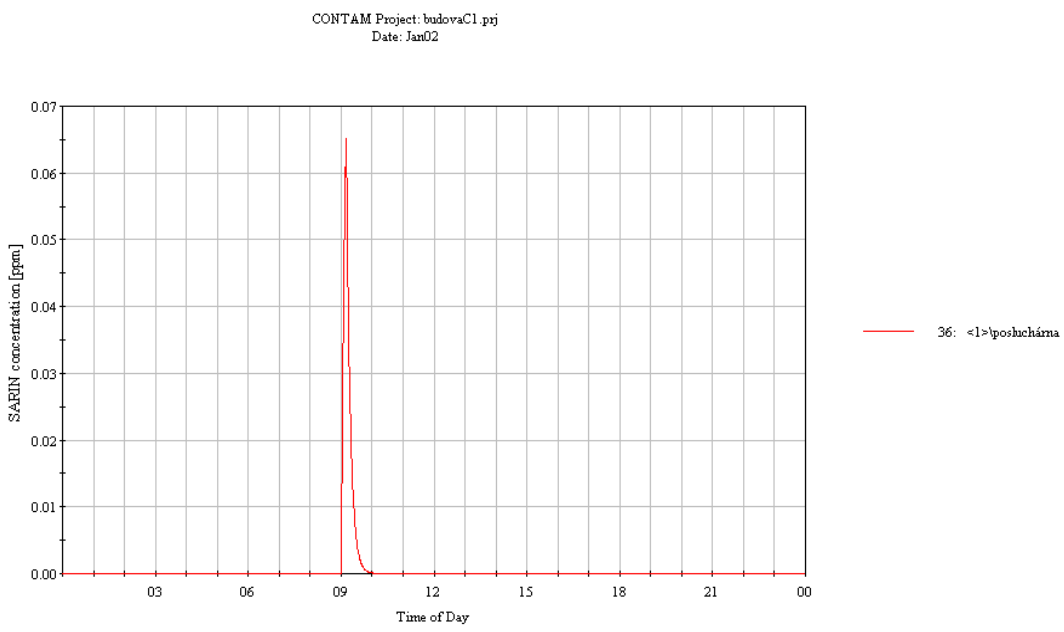

Figure 3: Leak without infiltration with air ventilation system on.

Another simulation was performed to find out the effects of infiltration through the non-sealed conference hall on Sarin concentration with different inside and outside temperatures. The air ventilation system was not in use at the time of the simulation. In figure 4 a slight decrease in Sarin concentration due to infiltration can be seen. 


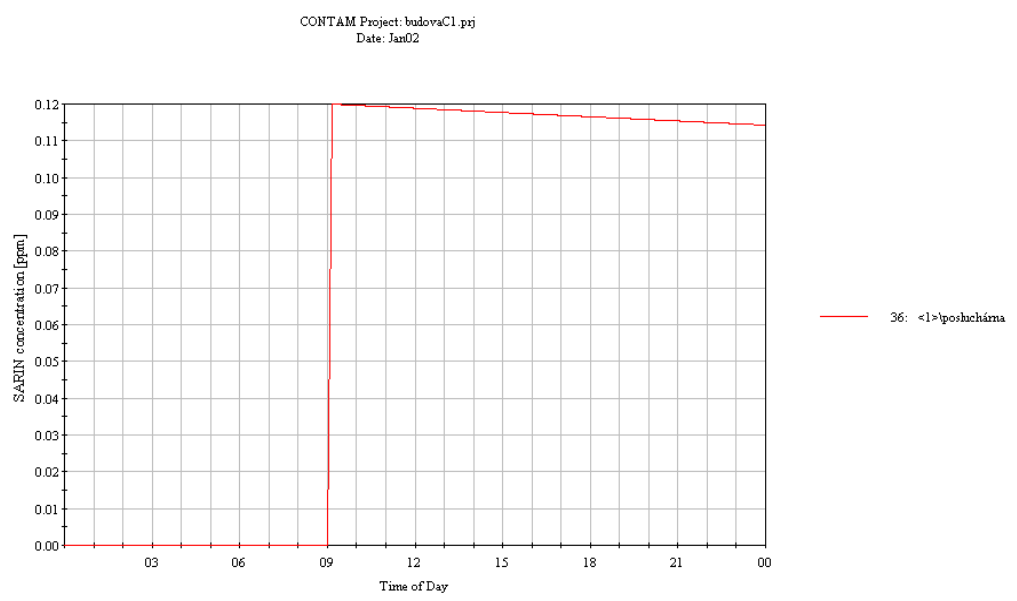

Figure 4: Leak with infiltration without air ventilation system.

CONTAM Project: budovaCl.pj Date: Jan02

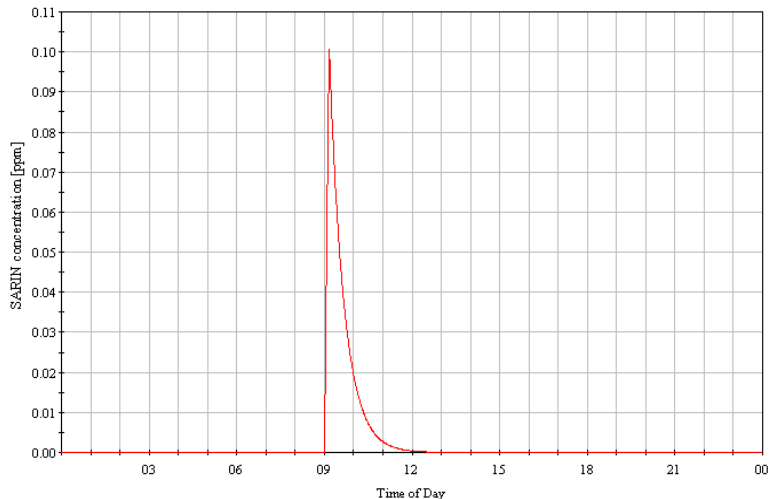

Figure 5: Leak with infiltration and air ventilation system with $50 \%$ recirculation.

The final simulation was performed with infiltration with an outside air temperature of $8^{\circ} \mathrm{C}$ and an inside temperature of $20^{\circ} \mathrm{C}$ with air ventilation system functioning between $7 \mathrm{am}$ and $8 \mathrm{pm}$, with $50 \%$ air recirculation from the conference hall. The results are shown in figure 5 .

\section{Conclusion}

With the use of simulations we have seen the capability of the CONTAM software program for analysing the spreading of CBR substances during a 
terrorist attack. According to the simulation examples it is obvious that the adding of infiltration and/or air ventilation systems are not sufficient to combat high Sarin concentrations and eliminate the risk of endangering the life and health of the people inside the building.

\section{References}

[1] Dudáček a kol., Ochrana před radioaktivními, chemickými a biologickými látkami - dílčí úkol č.2 Zvýšení bezpečnosti multifunkčních budov před rizikem teroristického útoku chemickými, biologickými a jadernými zbraněmi. Zprávy z řešení projektu SÚJ 10/2003, Ostrava VŠB - TUO 2003 -2005 .

[2] Fact sheet on exposure limits for Sarin (GB), July 1997, http://www.gulflink.osd.mil/dugway/low_lv_chem_fact.htm

[3] Georgie N. Walton, W. Start Dols, CONTAM $2.4 \overline{\text { User Guide and Program }}$ Documentation (NISTIR7251), NIST Gaithersburg, MD 20899-8633

[4] Chemická zbran̆ sarin, http://www.sweb.cz/armady-sveta/sarin.htm

[5] Středa Ladislav a kol., Bojové chemické látky ve vztahu k Úmluvě, Praha 2004 